\title{
Determinação da Exigência Nutricional de Treonina para Poedeiras Leves e Semipesadas 1
}

\author{
Sandra Roselí Valerio ${ }^{2}$, Paulo Rubens Soares ${ }^{3}$, Horacio Santiago Rostagno ${ }^{3}$, Martinho \\ de Almeida e Silva ${ }^{4}$, Luiz Fernando Teixeira Albino ${ }^{3}$, Geraldo Roberto Quintão Lana ${ }^{5}$, Cláudia \\ de Castro Goulart6, João Luís Kill ${ }^{7}$
}

\begin{abstract}
RESUMO - Desenvolveu-se este experimento com o objetivo de determinar a exigência nutricional de treonina para poedeiras leves e semipesadas no período de 21 a 36 semanas. Foram utilizadas 576 aves, 288 poedeiras leves e 288 semipesadas, durante quatro períodos experimentais de 28 dias cada. O delineamento experimental foi inteiramente casualizado em esquema fatorial 6 x 2 (níveis x marcas), com seis repetições e oito aves por unidade experimental. Os tratamentos consistiram em uma ração basal contendo $14,2 \%$ de proteína bruta, suplementada com cinco níveis de L-treonina $(0,025 ; 0,050 ; 0,075 ; 0,100$; e 0,125\%), resultando em um total de 0,510; 0,535; 0,$560 ; 0,585 ; 0,610 ;$ e $0,635 \%$ de treonina. O desempenho produtivo e a qualidade interna dos ovos foram avaliados. Consumo de ração, produção de ovos massa de ovos e o ganho de peso foram superiores para as poedeiras semipesadas. A produção e qualidade interna dos ovos, a conversão alimentar e o ganho de peso não foram influenciados pelos níveis de treonina utilizados. O nível de $0,510 \%$ de treonina, que corresponde a $515 \mathrm{mg} / \mathrm{ave} / \mathrm{dia}(0,423 \%$ de treonina digestível) e $535 \mathrm{mg} / \mathrm{ave} / \mathrm{dia}(0,440 \%$ de treonina digestível), foi suficiente para atender, satisfatoriamente, o desempenho e a qualidade interna dos ovos das poedeiras leves e semipesadas, respectivamente, para as características avaliadas.
\end{abstract}

Palavras-chave: poedeiras leves, qualidade interna dos ovos, semipesadas, treonina

\section{Determination of Threonine Nutritional Requirement for White-Egg and Brown-Egg Laying Hens}

\begin{abstract}
An experiment was carried out to determine the nutritional threonine requirement for white-egg and brown-egg laying hens, during a period from 21 to 36 weeks. Five hundred and seventy six laying hens, 288 from white-egg and 288 from brown-egg, were used during four experimental periods of 28 days each. A complete randomized blocks design in a fatorial arangement (level x trademarks), with six replicates (eight birds/replicate), was used. The treatments consisted on a basal diet with $14.2 \%$ crude protein supplemented with $0.025,0.050,0.075,0.100$, and $0.125 \%$ of L-threonine providing a total of $0.510,0.535,0.560,0.585,0.610$, and $0.635 \%$ of threonine. The productive performance and internal egg quality were evaluated. Feed intake, egg production, egg mass and weight gain were superior for the brown-egg laying hens. Egg production and internal egg quality, feed: gain ratio, body weight gain were not influenced by the used threonine levels. The level of $0,510 \%$ of threonine, that correspond to $515 \mathrm{mg} / \mathrm{hen} \cdot$ day $(0,423 \%$ of digestible threonine $)$ and $535 \mathrm{mg} / \mathrm{hen} \cdot$ day $(0,440 \%$ of digestible threonine), was sufficient to meet the performance and to the internal egg quality for the studied characteristics of both white-egg and brown-egg laying hens, respectively.
\end{abstract}

Key Words: internal egg quality, light-weight hens, requirement, semi-heavy hens, threonine

\section{Introdução}

As recomendações do nível protéico das rações de poedeiras baseiam-se principalmente, nas respostas de desempenho, quanto ao consumo de ração, à produção de ovos, qualidade dos ovos e conversão alimentar. ROSTAGNO et al. (1983) sugeriram, para as condições brasileiras, os níveis de
15,9 e $14,5 \%$ de proteína bruta (PB) para poedeiras, com base no consumo de 100 e $110 \mathrm{~g}$ de ração/ave/dia, respectivamente. Da mesma maneira, RHODIMET (1993) recomendou, para poedeiras leves e semipesadas, os níveis de 14,5 e 14,2\% PB, considerando consumo de 110 e $120 \mathrm{~g}$ de ração/ave/dia, respectivamente. Já o NATIONAL RESEARCH COUNCIL - NRC (1994) cita, como exigências para

\footnotetext{
1 Parte da Tese de Mestrado apresentada à Universidade Federal de Viçosa pela primeira autora.

2 Zootecnista. Estudante de Doutorado do Depto de Zootecnia da Universidade Federal de Viçosa. E.mail: svalerio@alunos.ufv.br

3 Professor do Depto de Zootecnia da Universidade Federal de Viçosa.

4 Professor da Escola de Veterinária - Universidade Federal de Minas Gerais.

5 Professor do Depto de Zootecnia da Universidade Federal Rural de Pernambuco.

6 Zootecnista. Mestre em Nutrição de Monogástricos pela Universidade Federal de Viçosa.

7 Estudante de Doutorado do Depto de Zootecnia da Universidade Federal de Viçosa.
} 
poedeiras leves e semipesadas, os níveis de 15,0 e $16,5 \%$ PB, com base no consumo de 100 e $110 \mathrm{~g}$ de ração/ave/dia, respectivamente.

Poedeiras recebendo rações contendo baixo conteúdo protéico, suplementadas com aminoácidos essenciais, têm apresentado bons resultados, mas não o máximo desempenho (JOHNSON e FISHER, 1959; NOVACEK e CARLSON, 1969; e Fisher e Morris (1970), citados por HARMS e RUSSELL, 1993), sugerindo que a suplementação com aminoácidos em rações com baixo nível de proteína não resulta, necessariamente, em produção máxima de massa de ovos.

KESHAVARZ et al. (1980) e KESHAVARZ (1984, 1986) observaram, em vários estudos, que o desempenho de aves alimentadas com rações de baixo conteúdo de proteína bruta e suplementadas com aminoácidos foi inferior àquelas aves, cuja ração continha altos níveis protéicos. Do mesmo modo, SUMMERS et al. (1991), alimentando poedeiras com rações contendo $10,0 \%$ PB, suplementadas com lisina, metionina, arginina e triptofano, obtiveram $11,0 \%$ menos massa de ovos, quando comparadas às aves, recebendo rações contendo $17,0 \% \mathrm{~PB}$, indicando que a produção e o peso de ovos respondem de maneira similar, ao elevar o nível protéico da ração. Já os trabalhos realizados por FERNANDEZ et al. (1973) demonstraram que ração contendo $13,0 \%$ de PB e suplementada com lisina e metionina pode ser tão eficiente quanto aquelas contendo 15,$0 ; 17,0 ;$ ou $18,0 \%$ $\mathrm{PB}$, para manter a produção e o tamanho de ovos. Resultados semelhantes foram encontrados por HARMS e RUSSELL (1993), quando determinaram melhor desempenho para as poedeiras consumindo rações com baixo conteúdo protéico $(14,89 \%)$ suplementadas com aminoácidos essenciais (metionina, lisina, arginina, treonina, triptofano e valina).

ADKINS et al. (1958) forneceram às poedeiras rações contendo níveis crescentes de L-treonina. A melhor produção de ovos foi obtida na ração com $0,42 \%$ de L-treonina. O consumo de ração para as poedeiras alimentadas com rações contendo elevados teores de treonina $(0,42 ; 0,47 ; 0,52 ; 0,57$; e $0,62 \%$ ) foi maior, correspondendo, em média, a 89,00 ; 79,$71 ; 99,85 ; 82,14$; e $85,71 \mathrm{~g} /$ ave/dia, respectivamente. Ocorreram perdas de peso de aproximadamente 412 e 77,6 g para as poedeiras, consumindo ração com 0,27 e $0,42 \%$ de L-treonina, respectivamente. Similarmente, HUYGHEB AERT e BUTLER (1991) observaram perda de peso das aves nas rações com baixas concentrações de treonina (inferiores a $0,40 \%$ ). Além disso, as poedeiras recebendo rações contendo 0,51 e $0,37 \%$ de treonina apresentaram, respectivamente, taxa de postura de 86,9 e $70,7 \%$, peso dos ovos de 60,5 e $55,0 \mathrm{~g}$, massa de ovo de 52,6 e 38,9 g/dia e conversão alimentar de 2,37 e 2,83 . Neste aspecto, o peso dos ovos foi mais sensível aos níveis de treonina que a taxa de postura, para poedeiras consumindo rações ligeiramente deficientes em aminoácidos.

Ao estudar o efeito da redução do nível protéico da ração de poedeiras e a relação com o requerimento de treonina, triptofano e isoleucina, WEERDEN et al. (1984) concluíram que o requerimento de treonina, durante o pico de produção, ficou entre 0,38 e $0,47 \%$, para consumo de 103,45 a $112,78 \mathrm{~g}$ de ração/ave/dia e conversão alimentar de 2,44 a 2,12, respectivamente.

Pesquisas com ratos (LEUNG et al., 1968; TEWS et al., 1979, 1980) e aves (DAVIS e AUSTIC,1982a) revelaram que as rações podem ser desbalanceadas em treonina, quando outros aminoácidos são adicionados às rações que estão adequadas em treonina. Por outro lado, KOELKEBECK et al. (1991), estudando o efeito do excesso de aminoácidos em poedeiras, durante o pico de postura, constataram que a adição de 1,0\% de lisina, metionina, treonina ou triptofano, em rações com 16,0\% PB, não apresentou efeitos significativos sobre o desempenho das poedeiras.

Devido a estas considerações, realizou-se este trabalho, objetivando determinar a exigência nutricional de treonina para poedeiras leves e semipesadas, no período de 21 a 36 semanas.

\section{Material e Métodos}

O experimento foi conduzido na seção de Avicultura do Departamento de Zootecnia, da Universidade Federal de Viçosa, utilizando 576 poedeiras, 288 aves Lohman Selected Leghorn (leves) e 288 Lohman Brown (semipesadas). As poedeiras com 21 semanas de idade foram submetidas a quatro períodos experimentais de 28 dias cada. O delineamento utilizado foi o inteiramente casualizado em esquema fatorial 6 x 2 (níveis x marcas), com seis repetições e oito aves por unidade experimental.

Os tratamentos consistiram em ração basal (Tabela 1) com 14,2\% de proteína bruta (PB), formulada de modo a satisfazer às recomendações nutricionais (ROSTAGNO et al., 1983), suplementada com cinco níveis de L-treonina $(0,025 ; 0,050 ; 0,075$; 0,100 ; e $0,125 \%$ ). Para o preparo das rações experimentais com os diferentes níveis de treonina, foram 
520 Rev. bras. zootec.

Tabela 1 - Composições da ração basal

Table 1 - Compositions of basal diet

\begin{tabular}{|c|c|}
\hline $\begin{array}{l}\text { Ingrediente } \\
\text { Ingredient }\end{array}$ & $(\%)$ \\
\hline Milho (Corn) & 37,00 \\
\hline Sorgo baixo tanino & 35,00 \\
\hline \multicolumn{2}{|l|}{ Low tanin sorghum } \\
\hline Farelo de soja (Soybean meal) & 9,42 \\
\hline Calcário(Limestone) & 8,76 \\
\hline Farinha de carne 40 & 4,54 \\
\hline \multicolumn{2}{|l|}{ Meat meal 40} \\
\hline Areia (Sand) & 2,13 \\
\hline Farelo glúten de milho & 2,00 \\
\hline \multicolumn{2}{|l|}{ Corn gluten meal } \\
\hline Sal (Salt) & 0,30 \\
\hline Suplemento vitamínico ${ }^{1}$ & 0,10 \\
\hline \multicolumn{2}{|l|}{ Vit. Supplem. } \\
\hline Suplemento mineral ${ }^{2}$ & 0,05 \\
\hline \multicolumn{2}{|l|}{ Min. Supplem. } \\
\hline Óleo vegetal (Vegetal oil) & 0,04 \\
\hline Cloreto de colina & 0,02 \\
\hline \multicolumn{2}{|l|}{ Choline chloride } \\
\hline L-lisina $\mathrm{HCl}(\mathrm{HCl}$ L-lysine $)$ & 0,25 \\
\hline DL-Metionina 99 (DL-Methionine 99) & 0,22 \\
\hline L-triptofano (L-tripthophan) & 0,02 \\
\hline L-treonina (L-threonine) & 0,00 \\
\hline BHT & 0,01 \\
\hline Amido (Corn starch) & 0,15 \\
\hline
\end{tabular}

Calculado

Calculated

$\mathrm{EM}(M E)^{3}, \mathrm{kcal} / \mathrm{kg} \quad 2768$

Triptofano (Tripthophan) ${ }^{3}, \% \quad 0,16$

Treonina digestível ${ }^{4}, \% \quad 0,419$

Digestible threonine

Sódio $(\text { Sodium })^{3}, \%$

0,16

Determinado(Determined)

Proteína bruta (Crude protein) ${ }^{5}, \% \quad 14,20$

$\mathrm{Ca}^{5}, \% \quad 4,10$

P total $(\text { Total } P)^{5}, \% \quad 0,57$

Lisina (Lysine $)^{6}, \% \quad 0,74$

Metionina + Cistina ${ }^{6}, \% \quad 0,58$

Methionine + Cystine

Metionina (Methionine) ${ }^{6}, \% \quad 0,40$

Treonina (Threonine) $)^{6}, \% \quad 0,51$

1 Rovimix matrizes (Roche): Vit. A-12.000.000 U.I.; Vit. $D_{3}-3.600 .000$ U.I.; Vit. $B_{1}-2500 \mathrm{mg}$; Vit. $B_{2}-8000 \mathrm{mg}$; Bit. $B_{6}-5000 \mathrm{mg}$; Ác. Pantotênico (Panthotenic acid) - $12.000 \mathrm{mg}$; Biotina (Biotine) - $200 \mathrm{mg}$; Vit. k3-3000 mg; Ác. fólico (Folic acid) - 1500 mg; Ác. nicotínico (Nicotinic acid) - $40.000 \mathrm{mg}$; Vit. $\mathrm{B}_{12}-20.000 \mathrm{mcg}$; Selênio (Selenium) - $150 \mathrm{mg}$; Veículo q.s.p. (Vehicle q.s.p.) - $100 \mathrm{~g}$.

2 Roligomix aves (Roche): Manganês (Manganese) - $160,0 \mathrm{~g}$; Ferro (Iron) -100,0 g; Cobre (Copper) - 20,0 g; Zinco (Zinc) - 100,0 g; Cobalto (Cobalt) - 2,0 g; lodo (lodine) - 2,0 g; Veículo, q.s.p. (Vehicle q.s.p.) $-1000 \mathrm{~g}$.

3 Composição calculada segundo ROSTAGNO et al. (1983). (Composition calculated according ROSTAGNO et al. (1983).

4 Coeficiente de digestibilidade da treonina: $82,2 \%$, segundo ROSTAGNO et al. (1996).

Coefficient of determination of threonine: $82.2 \%$ according ROSTAGNO et al. (1996).

5 Análises realizadas no Laboratório de Nutrição Animal do Departamento de Zootecnia - UFV.

Analyses were realized in the Animal Nutrition Lab of the Animal Science Department-UFV.

6 Análises realizadas no Laboratório da Nutris Tec. e Sist. Nutr. LTDA., Quatro Barras, Paraná.

Analyses were realized in the Nutris Tec. e Sist. Nutr. LTDA. Lab., Quatro Barras, Paraná feitas duas rações basais, sendo uma sem suplementação de L-treonina, mantendo o nível de $0,510 \%$ de treonina (tratamento 1) e a outra suplementada com L-treonina, para fornecer o nível máximo de treonina $(0,635 \%$, tratamento 6$)$. As duas rações foram misturadas proporcionalmente, de modo a fornecer os níveis intermediários de treonina. Dessa forma, os tratamentos foram:

Tratamento 1 - Basal, fornecendo total de $0,510 \%$ treonina;

Tratamento 2 - Basal $+0,025 \%$ treonina, fornecendo total de $0,535 \%$ treonina;

Tratamento 3 - Basal $+0,050 \%$ treonina, fornecendo total de $0,560 \%$ treonina;

Tratamento 4 - Basal $+0,075 \%$ treonina, fornecendo total de $0,585 \%$ treonina;

Tratamento 5 - Basal $+0,100 \%$ treonina, fornecendo total de $0,610 \%$ treonina; e

Tratamento 6 - Basal $+0,125 \%$ treonina, fornecendo total de $0,635 \%$ treonina.

As variáveis estudadas foram: consumo de ração (g/ave/dia), produção de ovos (\%), peso dos ovos (g), massa de ovos (g/ave/dia), ganho de peso corporal $(\mathrm{g})$, conversão alimentar e qualidade interna dos ovos (Unidade Haugh e Índice de Gema e Albúmen).

As aves foram criadas até a $17^{\mathrm{a}}$ semana de idade, em galpão com piso de maravalha, seguindo as recomendações contidas no manual da marca, sendo transferidas no início da $18^{\mathrm{a}}$ semana de idade para o galpão de postura. As poedeiras foram alojadas segundo o peso médio, de modo que todos os tratamentos no início do período experimental apresentassem aves com peso corporal semelhante. A distribuição dos tratamentos foi feita de forma que cada quatro gaiolas constituíssem uma repetição, sendo, portanto, duas aves por gaiola.

$\mathrm{O}$ experimento teve início quando as poedeiras atingiram 21 semanas de idade. As aves foram novamente pesadas individualmente, para terem seu peso médio inicial aferido, tendo em vista posterior cálculo de ganho de peso. O peso médio inicial e a taxa de postura inicial foram, respectivamente, $1319,26 \mathrm{~g} \pm$ $48,41 \mathrm{~g}$ e $47,92 \%$ para poedeiras leves e $1597,85 \mathrm{~g} \pm$ $38,35 \mathrm{~g}$ e $45,14 \%$ para as poedeiras semipesadas. O fornecimento de ração foi à vontade, durante todo o período experimental. O programa de luz utilizado seguiu as recomendações do manual da marca. $\mathrm{O}$ consumo de ração foi determinado ao final de cada período experimental (28 dias). Com base neste consumo e na porcentagem de treonina em cada 
tratamento, determinou-se o consumo de treonina em mg/ave/dia. A conversão alimentar foi expressa em termos de quilos de ração consumida por quilo de ovos produzidos.

A coleta de ovos foi realizada diariamente, e o cálculo de produção baseou-se no número de ovos/ave/dia. Os ovos foram pesados nos cinco últimos dias de cada período experimental, para o cálculo de peso e massa de ovo.

As Unidades Haugh (UH) foram tomadas pela amostragem dos ovos de cada tratamento e repetição, obtidos no segundo dia de cada pesagem, utilizando-se um aparelho de Unidade Haugh tipo AMES $\mathrm{S}-6428$, para medir a altura do albúmen, segundo EGG grading manual - EGM (1964). Os Índices de Gema (IG) e Albúmen (IA) foram calculados pela relação média dos diâmetros das gemas e albúmen, medidas por paquímetro. $\mathrm{O}$ ganho de peso foi calculado por diferença de peso das aves, no início e no final do experimento.

As análises químicas e bromatológicas das rações experimentais foram executadas de acordo com SILVA (1990). Os conteúdos de aminoácidos das rações basais foram obtidos de valores médios de determinações resultantes de análises laboratoriais. Os dados foram submetidos às análises estatísticas, utilizando-se o programa SAEG desenvolvido na UNIVERSIDADE FEDERAL DE VIÇOSA - UFV (1982). Os efeitos dos níveis de suplementação de Ltreonina foram estudados por meio de análise de variância e modelos de regressão linear e quadrática.

\section{Resultados e Discussão}

Os resultados referentes ao consumo médio de ração $(\mathrm{CR})$ e de treonina $(\mathrm{CT})$, à produção de ovos (PROD), ao peso de ovos (PO), à massa de ovos (MO) e à conversão alimentar (CA) das poedeiras leves e semipesadas, nos vários níveis de treonina, encontram-se na Tabela 2. O consumo de ração, a produção e massa de ovos e o ganho de peso foram superiores para as poedeiras semipesadas. Ambas as marcas apresentaram valores semelhantes para peso médio dos ovos e conversão alimentar (Tabelas 2 e 3 ).

Pode-se observar que houve variação no consumo médio de ração das aves leves, provavelmente em função do menor consumo de ração $(95,27 \mathrm{~g} / \mathrm{ave} / \mathrm{dia})$ das poedeiras que receberam a ração contendo $0,535 \%$ de treonina, em relação às aves submetidas à ração com $0,510 \%$ de treonina, que ingeriram $101,06 \mathrm{~g}$ de ração/ave/dia. Não foi encontrada expli- cação biológica para o menor consumo de ração observado nestas poedeiras. No entanto, houve efeito quadrático $(\mathrm{P}<0,05)$ e a exigência de treonina encontrada para as mesmas foi de $0,574 \%$, para consumo mínimo de 95,65 g de ração/ave/dia. Da mesma maneira, constatou-se este efeito sobre o consumo de treonina, possivelmente em virtude do consumo de ração. Para as poedeiras semipesadas, o consumo de treonina aumentou $(\mathrm{P}<0,05)$ linearmente, à medida que níveis crescentes de treonina foram adicionados à ração, mostrando que esses níveis não influenciaram o consumo de ração. As equações para consumo de ração e de treonina, ajustados por meio de regressão linear e quadrático para poedeiras leves e semipesadas, foram, respectivamente:

$$
\begin{aligned}
& \hat{Y}=450,956-1237,03 x+1076,70 x^{2} \quad\left(R^{2}=0,65\right) \\
& \hat{Y}=1,96692-5,92395 x+6,01770 x^{2} \quad\left(R^{2}=0,97\right) \\
& \hat{Y}=0,0378169-0,967480 x \quad\left(R^{2}=0,99\right)
\end{aligned}
$$

Os resultados obtidos divergem, em parte, dos encontrados por ADKINS et al. (1958), que constataram maior consumo de ração para as poedeiras alimentadas com maiores níveis de treonina, 0,42 a 0,62\%, que consumiram, em média, 374,0 a 531,0 mg de treonina/ave/dia, respectivamente. De maneira semelhante, WEERDEN et al. (1984) observaram, durante o pico de postura, variação no consumo de ração $(103,45$ a $112,78 \mathrm{~g} / \mathrm{ave} / \mathrm{dia})$, em poedeiras alimentadas com rações contendo 0,38 a $0,47 \%$ de treonina, correspondendo ao consumo de 393,0 a 530,0 mg de treonina/ave/dia. Já HUYGHEBAERT e BUTLER (1991) notaram que poedeiras alimentadas com rações contendo $0,51 \%$ de L-treonina, com consumo médio de 125,0 g/ave/dia e $637,5 \mathrm{mg}$ de treonina/ave/dia, apresentaram melhores resultados de desempenho que aves alimentadas com rações contendo $0,37 \%$ de L-treonina, que consumiram, em média, 111,0 g de ração/ave/dia e 410,70 mg de treonina/ave/dia.

As poedeiras leves e semipesadas atingiram o pico de postura com 26 semanas de idade, produzindo, respectivamente, 86,01 e 90,67\%, sendo estes resultados inferiores aos citados no manual da marca $(92,0$ a $95,0 \%$ e 90 a $93 \%)$.

Os níveis de treonina utilizados não influenciaram (P>0,01) a produção de ovos das aves leves e semipesadas. Estes resultados são divergentes daqueles encontrados por ADKINS et al. (1958), que obtiveram melhora na produção de ovos, à medida que níveis crescentes de treonina foram adicionados à ração. De maneira semelhante, HUYGHEBAERT e BUTLER (1991) constataram que poedeiras alimentadas com rações com $0,37 \%$ de treonina apre- 
522 Rev. bras. zootec.

Tabela 2 - Efeito dos níveis de treonina sobre o consumo médio de ração (CR, g/ave/dia) e de treonina (CT, mg/ave/dia,) produção (PROD, \%), peso (PO, g) e massa de ovos (MO, g/ave/dia) e conversão alimentar (CA, $\mathrm{kg})$ de poedeiras leves (PL) e semipesadas (PSP)

Table 2 - Effect of threonine levels on the average feed intake ( $F l, g / h e n / d a y)$, threonine intake (Tl, $\mathrm{mg} /$ hen/day), egg production (EP, \%), weight (EW, g) and mass (EM, g/hen/day) and feed:gain ratio (F:G, kg) of white-egg (LH) and brown-egg laying hens (SHH)

\begin{tabular}{|c|c|c|c|c|c|c|c|c|c|c|c|c|}
\hline \multirow{3}{*}{$\begin{array}{l}\text { Treonina (\%) } \\
\text { Threonine }\end{array}$} & \multicolumn{2}{|c|}{$\begin{array}{l}\text { CR } \\
F I\end{array}$} & \multicolumn{2}{|c|}{$\begin{array}{l}\text { CT } \\
\text { TI }\end{array}$} & \multicolumn{2}{|c|}{$\begin{array}{c}\mathrm{PROD}^{\mathrm{ns}} \\
E P^{n s}\end{array}$} & \multicolumn{2}{|c|}{$\begin{array}{l}\mathrm{PO} \\
E W\end{array}$} & \multicolumn{2}{|c|}{$\begin{array}{l}\mathrm{MO} \\
E M\end{array}$} & \multicolumn{2}{|c|}{$\begin{array}{l}\mathrm{CA}^{\mathrm{ns}} \\
F: G^{n s}\end{array}$} \\
\hline & $\mathrm{PL}^{2}$ & $\mathrm{PSP}^{\mathrm{ns}}$ & $\mathrm{PL}^{2}$ & $\mathrm{PSP}^{1}$ & PL & $\overline{\mathrm{PSP}}$ & $\mathrm{PL}^{2}$ & $\mathrm{PSP}^{\mathrm{ns}}$ & $P L^{2}$ & $\mathrm{PSP}^{\mathrm{n}} \mathrm{s}$ & $\mathrm{PL}$ & PSP \\
\hline & $L H^{2}$ & $S H H^{n s}$ & $L H^{2}$ & $S H H^{1}$ & $L H$ & SHH & $L H^{2}$ & $S H H^{n s}$ & $L H^{2}$ & $S H H^{n s}$ & $L H$ & $S H H$ \\
\hline 0,510 & 101,06 & 104,96 & 515,41 & 535,28 & 83,07 & 85,32 & 56,70 & 56,71 & 47,17 & 48,42 & 2,15 & 2,18 \\
\hline 0,535 & 95,27 & 104,17 & 509,67 & 557,31 & 76,57 & 85,38 & 55,84 & 55,90 & 42,79 & 47,78 & 2,25 & 2,19 \\
\hline 0,560 & 96,31 & 102,15 & 539,34 & 572,04 & 79,08 & 85,81 & 55,22 & 56,18 & 43,82 & 48,18 & 2,22 & 2,13 \\
\hline 0,585 & 97,40 & 102,52 & 569,80 & 599,78 & 82,07 & 85,02 & 55,51 & 56,76 & 45,63 & 48,31 & 2,15 & 2,13 \\
\hline 0,610 & 95,96 & 103,42 & 585,34 & 630,88 & 80,08 & 85,28 & 55,27 & 56,87 & 44,33 & 48,48 & 2,18 & 2,14 \\
\hline 0,635 & 99,69 & 103,13 & 633,03 & 654,90 & 81,68 & 86,07 & 56,89 & 56,26 & 46,50 & 48,42 & 2,15 & 2,15 \\
\hline Médias & $97,61^{b}$ & $103,39^{a}$ & $558,76^{\mathrm{b}}$ & $591,70^{\mathrm{a}}$ & $80,42^{b}$ & $85,48^{a}$ & $55,91^{\mathrm{a}}$ & $56,44^{\mathrm{a}}$ & $45,04^{b}$ & $48,27^{\mathrm{a}}$ & $2,18^{a}$ & $2,15^{\circ}$ \\
\hline $\mathrm{CV}(\%)$ & \multicolumn{2}{|c|}{4,59} & \multicolumn{2}{|c|}{4,57} & \multicolumn{2}{|c|}{5,93} & \multicolumn{2}{|c|}{2,48} & \multicolumn{2}{|c|}{6,19} & \multicolumn{2}{|c|}{4,45} \\
\hline
\end{tabular}

Médias seguidas de letras diferentes para cada variável diferem pelo Teste $F(P<0,05)$

Averages followed by different letters for each variable differ by test $F(P<.05)$.

1 Efeito linear do nível de treonina pelo teste $\mathrm{F}(\mathrm{P}<0,05)$ (Linear effect of threonine level by $F$ test $(P<.05)$

2 Efeito quadrático do nível de treonina pelo teste $\mathrm{F}(\mathrm{P}<0,05)$ (Quadratic effect of threonine level by $F$ test $(P<.05)$.

ns Não-significativo (Non significant).

Tabela 3 - Efeito dos níveis de treonina sobre ganho de peso (GP), unidade Haugh (UH), índice de gema (IG) e índice de albúmen (IA) de poedeiras leves (PL) e semipesadas (PSP) ${ }^{1}$

Table 3 - Effect of threonine levels on weight gain (WG), Haugh unit (HU), yolk index (YI) and albumen index (Al) of white-egg $(\mathrm{LH})$ and brown-egg laying hens $(\mathrm{SHH})^{1}$

\begin{tabular}{|c|c|c|c|c|c|c|c|c|}
\hline \multirow{3}{*}{$\begin{array}{l}\text { Treonina }(\%) \\
\text { Threonine }\end{array}$} & \multicolumn{2}{|c|}{$\begin{array}{c}\mathrm{GP}(\mathrm{g}) \\
W G \\
\end{array}$} & \multicolumn{2}{|c|}{$\begin{array}{l}\mathrm{UH} \\
H U \\
\end{array}$} & \multicolumn{2}{|c|}{$\begin{array}{l}\mathrm{IG} \\
Y I \\
\end{array}$} & \multicolumn{2}{|c|}{$\begin{array}{l}\text { IA } \\
A I\end{array}$} \\
\hline & PL & PSP & PL & $\overline{\mathrm{PSP}}$ & $\mathrm{PL}$ & PSP & $\mathrm{PL}$ & PSP \\
\hline & $L H$ & SHH & $L H$ & $\mathrm{SHH}$ & $L H$ & $\mathrm{SHH}$ & $L H$ & $\mathrm{SHH}$ \\
\hline 0,510 & 165,00 & 247,08 & 92,68 & 91,30 & 0,55 & 0,55 & 0,13 & 0,12 \\
\hline 0,535 & 151,99 & 297,29 & 93,30 & 91,66 & 0,55 & 0,55 & 0,14 & 0,12 \\
\hline 0,560 & 164,64 & 252,91 & 94,95 & 93,21 & 0,55 & 0,56 & 0,14 & 0,13 \\
\hline 0,585 & 110,00 & 233,84 & 93,49 & 91,66 & 0,55 & 0,55 & 0,14 & 0,13 \\
\hline 0,610 & 158,78 & 254,37 & 95,37 & 91,55 & 0,55 & 0,55 & 0,14 & 0,12 \\
\hline 0,635 & 147,29 & 207,08 & 94,22 & 91,55 & 0,54 & 0,55 & 0,14 & 0,12 \\
\hline Médias $^{2}$ & $149,62^{b}$ & $248,76^{\mathrm{a}}$ & $94,00^{\mathrm{a}}$ & $91,82^{b}$ & $0,55^{\mathrm{a}}$ & $0,55^{\mathrm{a}}$ & $0,14^{\mathrm{a}}$ & $0,12^{b}$ \\
\hline$\overline{\mathrm{CV}(\%)}$ & \multicolumn{2}{|c|}{28,16} & \multicolumn{2}{|c|}{2,77} & \multicolumn{2}{|c|}{2,88} & \multicolumn{2}{|c|}{7,72} \\
\hline
\end{tabular}

${ }^{1}$ Não-significativo $(P>0,05)$ (Non significant).

2 Médias seguidas de letras diferentes para cada variável diferem pelo teste $F(P<0,05)$.

Averages followed by different letters for each variable differ by test $F(P<.05)$.

sentaram menor taxa de postura $(70,7 \%)$ que aquelas recebendo rações contendo $0,51 \%$ de treonina $(89,6 \%)$. A menor produção de ovos observada para as poedeiras leves alimentadas com ração contendo $0,535 \%$ de treonina $(76,57 \%)$, em relação às poedeiras submetidas à ração com $0,510 \%$ de treonina $(83,07 \%)$, possivelmente foi ocasionada pelo menor consumo de ração $(95,27 \mathrm{~g} / \mathrm{ave} / \mathrm{dia})$ das aves que ingeriram menor quantidade de nutrientes (treonina, lisina, energia, proteína bruta e outros). Esta explicação está de acordo com os relatos de KESHAVARZ (1984), que verificou redução no desempenho das aves alimentadas com rações contendo $14,5 \%$ de proteína bruta, a qual provavelmente ocorreu em função da baixa ingestão de lisina e outros aminoácidos.

Similarmente, os valores para peso e massa de ovos, encontrados para as poedeiras leves e semipesadas, foram inferiores aos citados nos manuais das marcas, que indicam, respectivamente, ovos com 62,5 a 63,5 g e massa de ovo com 50,5 a 51,1 g/ave/dia. Resultados semelhantes foram observados por HARMS e RUSSELL (1993), que encontra- 
ram ovos com 55,8 g de peso e massa de ovo de 46,4 g/ave/dia. Entretanto, KESHAVARZ (1984) encontrou valores inferiores para peso $(51,1 \mathrm{~g})$ e massa de ovo (32,0 g/ave/dia), sugerindo que a suplementação com aminoácidos em rações com baixo conteúdo protéico não resulta em produção máxima de massa de ovos.

Por outro lado, REID (1976) e BRAGA (1978) encontraram resultados superiores para peso de ovos (60,2 e 62,6 g, respectivamente) e valores semelhantes para massa de ovos $(46,3$ e 50,4 g/ave/dia, respectivamente).

Pode-se verificar, entretanto, variação no peso dos ovos das aves leves, possivelmente em função dos menores consumo de ração $(95,27 \mathrm{~g} / \mathrm{ave} / \mathrm{dia})$ e peso dos ovos $(55,90 \mathrm{~g})$, resultantes do tratamento que continha $0,535 \%$ de treonina, em relação ao nível de $0,510 \%$ de treonina, com consumo de $101,06 \mathrm{~g}$ de ração/ ave/dia e peso de ovo de 56,70 g. Do mesmo modo, esta variação foi observada para a massa de ovos, provavelmente, em decorrência do menor consumo de ração das aves que receberam ração com $0,535 \%$ de treonina, as quais ingeriram 509,67 mg de treonina/ave/dia. As exigências de treonina obtidas para peso e massa de ovos foram $0,573 \%$ de treonina, para peso mínimo de 55,18 g e $0,570 \%$ de treonina, para massa mínima de ovos de 43,81 g/ave/dia. As equações para peso e massa de ovos, ajustadas por meio de regressão para as poedeiras leves, foram, respectivamente:

$$
\vec{P}=185,455-454,566 \mathrm{x}+396,539 \mathrm{x}^{2}\left(\mathrm{R}^{2}=0,88\right)
$$$$
\vec{P}=261,395-763,545 \mathrm{x}+669,872 \mathrm{x}^{2}\left(\mathrm{R}^{2}=0,47\right)
$$

Os resultados obtidos para peso de ovos estão de acordo com ADKINS et al. (1958), em que poedeiras alimentadas com níveis, variando de 0,42 a $0,62 \%$ de treonina na ração, produziram ovos com peso médio de 53,0 g. Todavia, o valor médio para massa de ovos (40,4 g/ave/dia) foi inferior ao encontrado neste trabalho. Já WEERDEN et al. (1984) observaram valores semelhantes para massa de ovo, que foram de 42,4 a $53,2 \mathrm{~g} /$ ave/dia, para níveis de 0,38 a $0,47 \%$ de treonina na ração. Por outro lado, HUYGHEBAERT e BUTLER (1991), testando rações contendo 0,51\% de treonina, obtiveram resultados superiores para peso $(60,5 \mathrm{~g})$ e massa de ovo (52,6 g/ave/dia). Portanto, os resultados encontrados neste experimento, para peso e massa de ovos, evidenciam que a ração contendo $0,510 \%$ de treonina atendeu às exigências nutricionais das poedeiras leves.

Os níveis de treonina não influenciaram $(\mathrm{P}>0,01)$ a conversão alimentar das poedeiras leves e semipesadas. Os resultados obtidos concordam com os de WEERDEN et al. (1984), ao utilizarem níveis de 0,38 a $0,47 \%$ de treonina na ração de poedeiras. Estes autores encontraram valores de conversão alimentar $(\mathrm{kg})$ entre 2,44 e 2,12. BRAGA (1978), trabalhando com duas linhagens de poedeiras legornes, não constatou diferença no valor da conversão alimentar (dz), que foi de 1,49. Ao elevar o nível protéico da ração de 13,0 para $15,0 \%$, esse autor obteve melhora na conversão. Resultados diferentes foram obtidos por PENZ e JENSEN (1991), os quais constataram que aves alimentadas com rações contendo 13,0 e 16,0\% de proteína bruta, suplementadas com lisina, apresentaram o mesmo valor de conversão alimentar (1,40). Já HUYGHEBAERT e BUTLER (1991) constataram melhora na conversão alimentar, à medida que níveis crescentes de treonina foram adicionados às rações. Apesar de serem observadas diferenças na conversão alimentar, entre as marcas comerciais, ainda há controvérsias quanto à influência do nível protéico da ração sobre a conversão em ovos.

HARMS e RUSSELL (1993) demonstraram que aves alimentadas com rações contendo baixo nível protéico suplementadas com lisina, treonina, arginina, valina, triptofano e metionina apresentaram pequena melhora na conversão alimentar $(1,77)$, quando comparadas com aves recebendo rações com baixo nível protéico, sem suplementação $(1,79)$.

Os níveis de treonina utilizados não influenciaram ( $\mathrm{P}>0,01)$ o ganho de peso e a qualidade interna dos ovos das poedeiras leves e semipesadas (Tabela 3 ). Portanto, os resultados para ganho de peso evidenciaram que não houve deficiência de treonina na ração. Ao contrário, ADKINS et al. (1958) encontraram perda de peso de, aproximadamente, 412,0 e 77,6 g, para as poedeiras alimentadas com rações contendo 0,27 e $0,42 \%$ de treonina, respectivamente. Da mesma forma, HUYGHEBAERT e BUTLER (1991) observaram perda de peso (média de 82,0 g) das aves, ao serem fornecidas rações contendo baixas concentrações de treonina ou inferiores a $0,40 \%$.

Os resultados para qualidade interna dos ovos também demonstraram que não houve deficiência de treonina na ração com $0,510 \%$. HARMS e DOUGLAS (1960), utilizando níveis protéicos, variando de 14,7 a 16,7\%, encontraram melhores resultados de Unidade Haugh para as aves que receberam rações contendo $14,7 \%$ de proteína bruta. BRAGA (1978) concluiu que os valores de Unidade Haugh não foram influenciados pelos níveis protéicos e energéticos. No entanto, HAMILTON (1978), 
fornecendo rações com 17,0\% de proteína bruta, suplementadas com lisina e metionina, apresentaram valor superior de Unidade Haugh $(83,34)$, quando comparadas com teores de 15,0 e 13,0\% de proteína bruta com suplementação. CARMO (1981) constatou que as aves alimentadas com rações contendo 13,0 e 12,0\% de proteína sem suplementação de metionina apresentaram valores de Unidades Haugh superiores aos das poedeiras submetidas à ração testemunha com $15,0 \%$ de proteína.

\section{Conclusões}

O nível de $0,510 \%$ de treonina, correspondendo a $515 \mathrm{mg} / \mathrm{ave} / \mathrm{dia}(0,423 \%$ de treonina digestível $)$ e 535 $\mathrm{mg} / \mathrm{ave} / \mathrm{dia}(0,440 \%$ de treonina digestível), foi suficiente para atender, satisfatoriamente, o desempenho e a qualidade interna dos ovos das poedeiras leves e semipesadas, respectivamente, para as características avaliadas.

\section{Referências Bibliográficas}

ADKINS, J.S., MILLER, E.C., BIRD, H.R. et al. 1958. An estimate of the threonine requirement of the laying hen. Poult. Sci., 37(6):1362-67.

BRAGA, D.F. Níveis de energia e proteína para duas linhagens de poedeiras legornes. Viçosa, MG: UFV, 1978. 54p. Dissertação (Mestrado em Zootecnia) - Universidade Federal de Viçosa, 1978.

CALDERON, V.M., JENSEN, L.S. 1990. The requirement for sulfur amino acid by laying hens as influenced by the protein concentration. Poult. Sci., 69(6):934-44.

CARMO, M.B. Niveis de proteína e de aminoácidos sulfurosos em rações de galinhas poedeiras sob regime de alta temperatura. Viçosa, MG: UFV, 1981. 104p. Dissertação (Mestrado em Zootecnia) - Universidade Federal de Viçosa, 1981.

DAVIS, A.T., AUSTIC, R.E. 1982a. Threonine imbalance and the threonine requirement of the chicken. J. Nutr., 112(11):2170-76.

EGG grading manual - EGM. Washington, D.C.: Departament of Agriculture, Consumer and Marketing Service, 1964. 64p. (Agriculture handbook, 75).

FERNANDEZ, R., SALMAN, A.J., McGINNIS, J. 1973. Effect of feeding different protein levels and of changing protein level on egg production. Poult. Sci., 52(1):64-69.

HAMILTON, R.M.G. 1978. The effects of dietary protein level on productive performance and egg quality of four strains of white leghorn hens. Poult. Sci., 57(5):1355-64.

HARMS, R.H., DOUGLAS, C.R. 1960. Relationships of rate of egg production as affected by feed to Haugh units of eggs. Poult. Sci., 39(1):75-86.

HARMS, R.H., RUSSELL, G.B. 1993. Optimizing egg mass with amino acid supplementation of a low-protein diet. Poult. Sci., 72(10):1892-96.

HUYGHEBAERT, G., BUTLER, E.A. 1991. Optimum threonine requirement of laying hens. Br. Poult. Sci., 32(3):575-82.

JENSEN, L.S., CALDERON, V.M., MENDONÇA JR., C.X. 1990. Response to tryptophan of laying hens fed practical diets varying in protein concentration. Poult. Sci.,69(11):1956-65.

JOHNSON, D., FISHER, H. 1959. The amino acid requirement of laying hens. 4. Supplying minimal levels of essential amino acids from natural feedstuffs. Poult. Sci., 38(1):149-52.

KESHAVARZ, K. 1986. The effect of dietary protein levels in pre and post-peak production periods on performance of laying hens. Nutr. Rep. Int., 34(3):473-87.

KESHAVARZ, K. 1984. The effect of dietary protein levels in the rearing and laying periods on performance of white leghorn chickens. Poult. Sci., 63(11):2229-40.

KESHAVARZ, K., DALE, N.M., FULLER, H.L. 1980. The use of non-protein nitrogen compounds, sugar beet molasses and laying rations. Poult. Sci., 59(11):2492-99.

KOELKEBECK, K.W., BAKER, D.H., HAN, Y. et al. 1991. Research note: effect of excess lysine, methionine, threonine or tryptophan on production performance of laying hens. Poult. Sci., 70(7):1651-53.

LEUNG, P.M.B., ROGERS, Q.R., HARPER, A.E. 1968. Effect of amino acid imbalance on plasma and tissue-free amino acids in the rat. J. Nutr., 96(3):303-18.

NATIONAL RESEARCH COUNCIL - NRC. 1994. Nutrient requirement of poultry. 9. ed. Washington, D.C.: National Academy Press. 155p.

NOVACEK, E.J., CARLSON, C.W. 1969. Low protein cagelayer diets and amino acids. Poult. Sci., 48(4):1490-1969.

PENZ JR., A.M., JENSEN, L.S. 1991. Influence of protein concentration, amino acid supplementation, and daily time of acess to high or low-protein diets on egg weight and components in laying hens. Poult. Sci., 70(12):2460-66.

REID, B.L. 1976. An estimated daily protein requirements of laying hens. Poult. Sci., 55(5):1641-45.

RHODIMET feed formulation guide. 6. ed. France: RhônePoulenc Animal Nutrition, 1993. 39p.

ROSTAGNO, H.S., BARBARINO JR., P., BARBOZA, W.A. Exigências nutricionais das aves determinadas no Brasil. In: SIMPÓSIO INTERNACIONAL SOBRE EXIGÊNCIAS NUTRICIONAIS DE AVES E SUÍNOS, 1996, Viçosa. Anais.. Viçosa, 1996. p.102.

ROSTAGNO, H.S., SILVA, D.J., COSTA, P.M.A. et al. 1983 Composição dos alimentos e exigências nutricionais de aves e suínos: tabelas brasileiras. Viçosa, MG: UFV. 61p.

SILVA, D.J. 1990. Análise de alimentos: métodos químicos e biológicos. 2. ed. Viçosa, MG: UFV. 166p.

SUMMERS, J.D., ATKINSON, J.L., SPRATT, D. 1991. Supplementation of a low protein diet in an attempt to optimize egg mass output. Can. J. Anim. Sci., 71(1):211-220.

TEWS, J.K., KIM, Y.W.L., HARPER, A.E. 1979. Induction of threonine imbalance by dispensable amino acids: relation to competition for amino acid transport into brain. J. Nutr., 109(2):304-15.

TEWS, J.K., KIM, Y.W.L., HARPER, A.E. 1980. Induction of threonine imbalance by dispensable amino acids: relationships between tissue amino acids and diet in rats. $J$. Nutr., 110(3):394-408.

UNIVERSIDADE FEDERAL DE VIÇOSA. Central de Processamento de Dados - UFV-CPD. SAEG - Sistema para análise estatística e genética. Viçosa, MG, 1982.59p.

WEERDEN, E.J. van, SCHUTTE, J.E., BERTRAM, H.L. Protein and amino acid requirements of laying hens. In: WORLDS POULTRY CONGRESS AND EXHIBITON, 17, 1984, Helsinki. Proceedings... Finland [s. n.], 1984. p.260-262.

Recebido em: 16/09/98 Aceito em: 17/09/99 